\section{Male-to-female sex ratios of abnormalities detected by fluorescence in situ hybridization in a population of chronic lymphocytic leukemia patients}

\author{
Eduardo S. Cantú, ${ }^{1}$ John R. McGill, ${ }^{2}$ \\ Christine F. Stephenson, ${ }^{3}$ \\ Heidi M. Hoffmann, ${ }^{4}$ Lihua Tang, ${ }^{5}$ \\ Jim Yan, ${ }^{5}$ Armand B. Glassman ${ }^{6}$ \\ ${ }^{1}$ Integrated Oncology, LabCorp Specialty \\ Testing Group, Phoenix, AZ; ${ }^{2}$ Miraca Life \\ Sciences, Phoenix, AZ; ${ }^{3}$ Hematologics, Inc. \\ Seattle, WA; ${ }^{4}$ Integrated Genetics, \\ Information Technology, Westborough, \\ MA; ${ }^{5}$ Research and Bioinformatics, \\ Laboratory Corporation of America \\ Holdings, Durham, NC; ${ }^{6}$ Department of \\ Microbiology \& Immunology, Medical \\ University of South Carolina, Charleston, \\ SC, USA
}

\section{Abstract}

Distorted sex ratios occur in hematologic disorders. For example, chronic lymphocytic leukemia (CLL) displays disproportionate sex ratios with a large male excess. However, the underlying genetics for these disparities are poorly understood, and gender differences for specific cytogenetic abnormalities have not been carefully investigated. We sought to provide an initial characterization of gender representation in genetic abnormalities in CLL by using fluorescence in situ hybridization (FISH). We confirm the well known skewed male-tofemale (M/F sex ratio) of $\sim 1.5$ in our CLL study population, but also determine the genotypic $M / F$ sex ratio values corresponding to specific FISH DNA probes. Genetic changes in CLL detectable by four FISH probes were statistically compared with respect to gender. Initial FISH evaluations of 4698 CLL patients were retrospectively examined and new findings of the genotypic $M / F$ sex ratios for these probes are reported. This study represents the largest CLL survey conducted in the United States using FISH probes. The CLL database demonstrated that FISH abnormalities (trisomy 12, 13q14.3 deletion and 17p13.1 deletion) probes had skewed $\mathrm{M} / \mathrm{F}$ ratios of $\sim 1.5$. Also, by statistical analysis it was shown that ATM gene loss (11q22.3q23.1 deletion) solely or with other abnormalities was considerably higher in males with an M/F ratio of 2.5 and significantly different from $M / F$ ratios of 1.0 or 1.5 . We hypothesize that interactions involving these autosomal abnormalities (trisomy 12, and deletions of
$11 q 22.3,13 q 14.3$, and $17 \mathrm{p} 13.1$ ), and the sex chromosomes may provide the genetic basis for the altered phenotypic $M / F$ ratio in CLL.

\section{Introduction}

Chronic lymphocytic leukemia (CLL) is the most commonly found leukemia in the adult population of the Western world and of clinical interest because of its prevalence. It is a neoplasm of monomorphic small round B lymphocytes which can be observed in peripheral blood, bone marrow, and/or lymph nodes. ${ }^{1}$ It is likely that CLL has a multifactorial mode of inheritance with both genetic and environmental components. ${ }^{2}$ This is indicated by the significant level of clinical heterogeneity found in CLL. ${ }^{3}$ However, of all hematologic neoplasms, CLL is reported to have the highest genetic predisposition and like many other hematologic malignancies, ${ }^{4}$ development of CLL is found to be much higher in males than in females with a corresponding $\mathrm{M} / \mathrm{F}$ sex ratio of at least 1.5 or higher. ${ }^{5}$ Although the clinical (phenotypic) $\mathrm{M} / \mathrm{F}$ sex ratio for CLL has been well documented, the genetic (genotypic) M/F sex ratios associated with abnormal fluorescence in situ hybridization (FISH) probes have not. For these reasons, CLL represents an attractive cancer entity in which to evaluate what genetic impact, if any, gender may have on its development.

Genetic studies of sex ratio disparities in human neoplasms have been few, perhaps, because of the relative inaccessibility of investigational materials including appropriate databases which could be informative. It follows that the genetic basis for this phenomenon remains largely unknown and our understanding of it very limited. Since our laboratory has collected clinical and laboratory data over many years on major categories of cancers including CLL, review and analyses of these data presented an opportunity to examine certain aspects of this question. In order to better study the nature of the multifactorial components in CLL, we determined the representation of genetic abnormalities detected by four defined FISH probes, with respect to male and female CLL patients. By this approach, our study addressed not only what the $\mathrm{M} / \mathrm{F}$ ratio is in CLL patients having the clinical phenotype, but also the M/F ratio in patients who have a genotype which included specific FISH abnormalities. These results provided a genetic basis for the notion that the FISH abnormalities found underlie the phenotypic $\mathrm{M} / \mathrm{F}$ sex ratio and also that they may be sex chromosomes ( $\mathrm{X}$ and/or $\mathrm{Y}$ ) influenced.
Correspondence: Eduardo S. Cantú, Integrated Oncology, LabCorp Specialty Testing Group Cytogenetics \& FISH Laboratories, $4310 \mathrm{E}$. Cotton Center Boulevard, Suite 120, Phoenix, AZ 85040, USA.

Tel.+1.602.4953809 - Fax: + 1.602.2547340

E-mail: cantue@labcorp.com

Key words: sex ratios, CLL, FISH.

Contributions: ESC, research idea, research, rough draft, revisions and final version of the manuscript; JRMG, refining the research idea, assisted with the research and revisions of the manuscript; CFS, design of the research project, critical review of the manuscript; HMH, collected, organized and anonimyzed all the data; drafted Materials and Methods section; LT, statistical analyses, interpretation of the data, drafting parts of the Results section; JY, statistical analyses and interpretation of the data, conclusions and revisions; $\mathrm{ABG}$, provided expertise in the clinical aspects of CLL, valuable guidance, advice, ideas and contributed to revisions of the manuscript.

Conflict of interests: ESC, HMH, LT, and JY work for companies under the umbrella of Laboratory Corporation of America ${ }^{\circledR}$ Holdings. JRM, CFS and $\mathrm{ABG}$ declare no competing interests.

Funding: none.

Received for publication: 27 October 2012.

Revision received: 16 January 2013.

Accepted for publication: 24 January 2013

This work is licensed under a Creative Commons Attribution NonCommercial 3.0 License (CC BYNC 3.0).

(O)Copyright E.S. Cantú et al., 2013

Licensee PAGEPress, Italy

Hematology Reports 2013; 5:e4

doi:10.4081/hr.2013.e4

\section{Materials and Methods}

Chronic lymphocytic leukemia-fluorescence in situ hybridization panel

CLL FISH results in the database are derived from testing done on cytological preparations made from peripheral blood or bone marrow specimens submitted for CLL evaluation. These specimens were from patients with or suspected CLL. FISH analyses were conducted using a FISH panel of DNA probes specific for the ATM gene (11q22.3-q23.1), chromosome 12 centromere (D12Z3 locus), the D13S319 locus (13q14.3), and the TP53 gene (17p13.1) commercially available from Vysis ${ }^{\circledR}$ (an Abbott company), Downers Grove, IL. The prognostic value and characterization of these DNA probes have been reported in the literature. ${ }^{6-9}$ The technical protocols for FISH testing (hybridization of probes and detection of 
hybridization signals) were those recommended by the manufacturer. Microscopic studies were conducted by experienced technologists, then reviewed and interpreted by board-certified cytogeneticists. These FISH test results were then archived in a computer-based database from which data were retrieved and statistically analyzed.

\section{Database}

Data of FISH results from all Integrated Oncology laboratories, a business unit of Esoterix Genetic Laboratories, LLC, using the same DNA FISH probes to evaluate CLL patients were collected, reviewed, and statistically evaluated. The data contained entries of CLL-FISH panels performed during the period of 11/13/2005 through 10/20/2009. 4698 CLL FISH panels were found. These panels were specifically used for CLL studies, and results were used only when the entire CLL panel was applied in order to clearly identify only those patients having or suspected of having CLL. Also, CLL panel probe results were those used only for the initial FISH evaluation of newly diagnosed CLL patient-and did not involve repeat studies on the same patient.

This investigation was conducted in a fashion in which laboratory results had no patientidentity associations, in order to conform to privacy guidelines and patient confidentiality.

\section{Statistical analyses}

The data was first collected in a Microsoft Excel spreadsheet. This data was then imported into SAS9.2 and formatted by SAS DATA Step and analyzed by SAS procedures for one side Binomial test and Chi-Square test. The one-side Binomial tests were used to evaluate the sex ratio with respect to the abnormalities found for each of the probes used. Two abnormal categories were considered. The first category represented all abnormal panels having only a single abnormality per panel, for each probe. The second category included those having any abnormality with respect to a given probe whether it appeared as a single abnormality or in combination with other abnormalities. The Binomial test took into account the frequency of an abnormality or abnormalities (according to the categories describe above) in a pool of data (total number of normal and abnormal panels) for each of the FISH probes considered, and compared the results obtained for the male group with results obtained for the female group. Essentially, the mean value for positive results (all having the same abnormality +) versus total results (positive results plus normal having 0 abnormalities), was compared between males and females for each of the probe categories described above. The odds ratio (OR) and $95 \%$ confidence interval $(\mathrm{CI})$ values were derived from the one side Binomial test while the P-values were determined by the
Chi-Square tests. Statistical significance was defined as a P-value of .05 or less.

\section{Results}

A characterization of the study population evaluated by the CLL-FISH panel is given in
Table 1, and a summary of general observations are provided in Table 2. For example, Table 2 shows that there were a total of 2773 (59.0\%) individual abnormal FISH panels in the 4698 total FISH panels applied to the CLL patient study group. Of the abnormal panels, 1711 were male and 1062 were female for an $\mathrm{M} / \mathrm{F}$ sex ratio of 1.61. Other comparisons of the genders concerning data collected by this study

Table 1. Study population evaluated by the chronic lymphocytic leukemia-fluorescence in situ hybridization panel.

\begin{tabular}{ll}
\hline $\begin{array}{l}\text { Patients } \\
\text { Evaluation }\end{array}$ & $\begin{array}{l}\text { Patients with or with suspected diagnosis of chronic lymphocytic leukemia } \\
\text { Only initial FISH evaluations for these patients were used (no follow-up or } \\
\text { repeat studies were included) }\end{array}$ \\
\hline $\begin{array}{l}\text { Data collection } \\
\text { Range of age }\end{array}$ & $\begin{array}{l}\text { From 11/13/2005 through 10/20/2009 } \\
\text { Males: 26-102 years - Females: 25-100 years }\end{array}$ \\
\hline Gender & Studied only if gender was known to be either male or female \\
Geographic distribution & USA \\
\hline $\begin{array}{l}\text { Specimen type used } \\
\text { FISH results }\end{array}$ & $\begin{array}{l}\text { Peripheral blood or bone marrow } \\
\text { Considered positive if outside the established normal limits for each of the } \\
\text { probes used }\end{array}$
\end{tabular}

Table 2. Summary of observations and comparisons made with respect to gender.

1. 4661 CLL-FISH panels were used for the statistical analysis.

2. 2805 panels were used to evaluate male CLL patients ( $60.2 \%$ of total panels). Of these, 1711 panels (60.5\%) were abnormal [for one or more probe(s)].

3. 1856 panels were used to evaluate female CLL patients ( $39.8 \%$ of total panels). Of these, 1062 panels (56.8\%) were abnormal [for one or more probe(s)].

4. The male-to-female ratio of total panels was 1.51. The male-to-female sex ratio for abnormal panels was 1.61 .

5. $\mathrm{M} / \mathrm{F}$ sex ratios were determined for:

1) category showing only FISH abnormalities

2) for category showing only normal FISH results

3) for category of all patients either having normal or abnormal FISH.

6. Abnormal to normal result ratios were also determined with respect to either male or female gender.

7. Odds ratio and Chi-Square statistical analyses were applied to evaluate whether the $\mathrm{M} / \mathrm{F}$ sex ratio was the same for each of the probes used

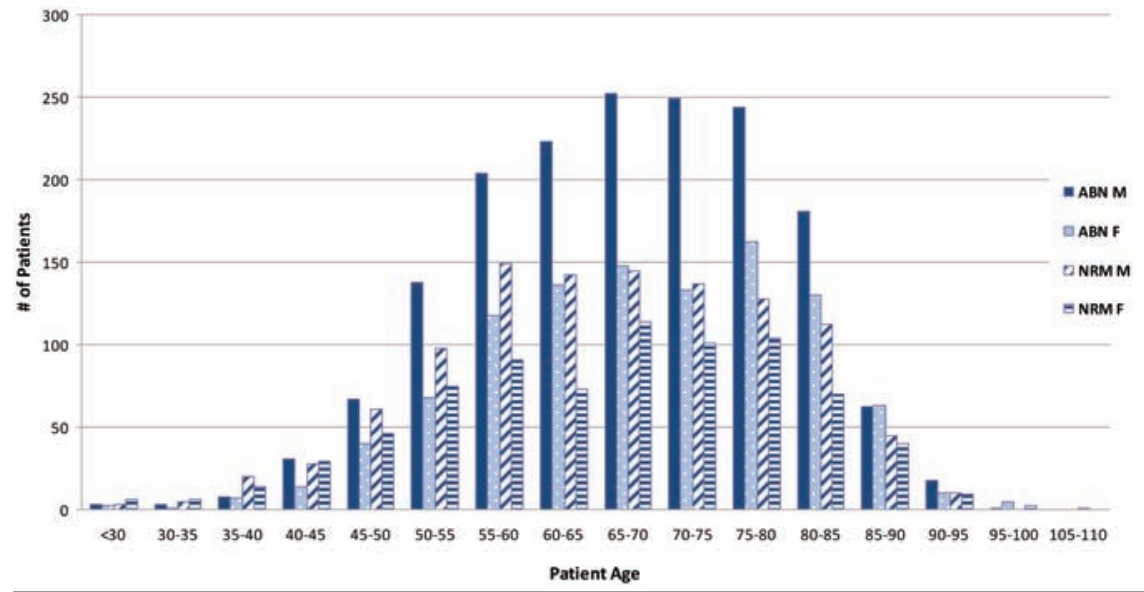

Figure 1. Distribution of the chronic lymphocytic leukemia study population by age and gender. 
Table 3. Male-to-female sex ratio for fluorescence in situ hybridization (FISH) abnormalities, FISH normal results and total FISH tests for each of the probes used to evaluate the chronic lymphocytic leukemia study population.

\begin{tabular}{|c|c|c|c|c|c|c|c|c|c|c|c|}
\hline \multirow[t]{2}{*}{ Probes } & \multirow[b]{2}{*}{ Male } & \multicolumn{3}{|c|}{ Abnormals } & \multicolumn{4}{|c|}{ Normals } & \multirow{2}{*}{$\begin{array}{c}\mathrm{Abo}+\text { Noro } / \mathrm{Ab}+\text { +Nor? } \\
\delta^{3} / ? \text { ratio }\end{array}$} & \multirow{2}{*}{ 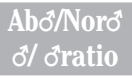 } & \multirow{2}{*}{$\begin{array}{l}\text { Ab\%/Norf } \\
\text { क/qratio }\end{array}$} \\
\hline & & Female & Totals & $3 / 9$ ratio & Male & Female & Totals & ô + ratio & & & \\
\hline \multicolumn{12}{|l|}{ Single only } \\
\hline $11 q 22.3$ (ATM) V & 99 & 39 & 138 & 2.54 & 2706 & 1817 & 4523 & 1.49 & 1.51 & 0.037 & 0.021 \\
\hline 12 centromere $\mathrm{V}$ & 277 & 195 & 472 & 1.42 & 2550 & 1673 & 4223 & 1.52 & 1.51 & 0.110 & 0.117 \\
\hline 13q14.3(D13S319) V & 804 & 523 & 1327 & 1.54 & 2011 & 1340 & 3351 & 1.52 & 1.51 & 0.399 & 0.390 \\
\hline 17p13.1(p53 gene) V & 57 & 41 & 98 & 1.39 & 2764 & 1780 & 4544 & 1.51 & 1.55 & 0.021 & 0.023 \\
\hline \multicolumn{12}{|c|}{ All abnormalities (single + multiple) } \\
\hline 11q22.3(ATM) V & 321 & 137 & 458 & 2.34 & 2435 & 1708 & 4143 & 1.45 & 1.43 & 0.132 & 0.080 \\
\hline 12 centromere V & 471 & 302 & 773 & 1.56 & 2340 & 1556 & 3896 & 1.50 & 1.50 & 0.201 & 0.194 \\
\hline 13q14.3(D13S319) V & 1217 & 766 & 1983 & 1.59 & 1573 & 1066 & 2639 & 1.46 & 1.58 & 0.774 & 0.719 \\
\hline 17pl3.1(p53 gene) V & 235 & 157 & 392 & 1.5 & 2576 & 1703 & 4279 & 1.52 & 1.51 & 0.091 & 0.092 \\
\hline
\end{tabular}

Table 4. Statistical analyses of abnormalities found in the chronic lymphocytic leukemia study population evaluated by the fluorescence in situ hybridization panel.

\begin{tabular}{|c|c|c|c|c|c|c|c|}
\hline Abnormalities & $\mathrm{O}^{\mathrm{J}} \mathrm{Ab}$ & olNor & ९Ab & PNor & P-value & Odds ratio & $95 \%$ CI of odds ratio \\
\hline \multicolumn{8}{|l|}{ Single abnormalities } \\
\hline $11 q 22.3$ (ATM) V & 99 & 2706 & 39 & 1817 & 0.0049 & 1.7045 & $(1.1712,2.4807)$ \\
\hline 12 centromere V & 277 & 2550 & 195 & 1673 & 0.4749 & 0.9320 & $(0.7681,1.1307)$ \\
\hline 13q14.3(D13S319) V & 804 & 2011 & 523 & 1340 & 0.7168 & 1.0243 & $(0.8995,1.1666)$ \\
\hline 17p13.1(p53 gene) V & 57 & 2764 & 41 & 1780 & 0.5930 & 0.8953 & $(0.5967,1.3434)$ \\
\hline \multicolumn{8}{|c|}{ All abnormalities (single + multiple) } \\
\hline $11 \mathrm{q} 22.3$ (ATM) V & 321 & 2435 & 137 & 1708 & $2.70-6$ & 1.6435 & $(1.3331,2.0263)$ \\
\hline 12 centromere $\mathrm{V}$ & 471 & 2340 & 302 & 1556 & 0.6518 & 1.0371 & $(0.8854,1.2147)$ \\
\hline 13q14.3(D13S319) V & 1217 & 1573 & 766 & 1066 & 0.2245 & 1.0767 & $(0.9557,1.2130)$ \\
\hline 17p13.1(p53 gene) V & 235 & 2576 & 157 & 1703 & 0.9223 & 0.9895 & $(0.8012,1.2221)$ \\
\hline
\end{tabular}

$\mathrm{Ab}$, abnormals, Nor, normal; CI, confidence interval.

are also reported in Table 2.

Table 3 shows the M/F ratios of FISH results for the study population of CLL patients in categories of abnormal results (either as a single abnormality or as a single abnormality plus multiple abnormalities), normal results and total results (normal and abnormal) with respect to gender. There were 2035 results that appeared as only single abnormalities, and 3606 results that appeared as single plus other abnormalities combined (artificially inflated since abnormalities were used multiple times). The most frequently found single abnormality was the deletion of $13 q 14.3$ (1327 abnormal results: $65.2 \%$ ), followed by trisomy 12 (472 abnormal: 23.2\%), then deletion of 11q22.3 (138 abnormal: 6.8\%), and least frequent was deletion of $17 \mathrm{p} 13.1$ (98 abnormal: $4.8 \%$ ). The sex ratio values for the FISH probes ranged from a low value of 1.39 to a high value of 2.54. With the exception of the sex ratio found for the ATP gene (2.54), the rest of the sex ratios for FISH abnormalities ranged from 1.39 to 1.54 , clustering around 1.5. From Table 3 , it should be noted that the Ab/Nor ratio for each of the probes was not significantly different from each other except for the ATM probe. This suggest that proportionality of abnormal results reflect the phenotypic representation of CLL clinically in our study population except for abnormalities of the ATM gene which is over-represented in male from that expected.
Figure 1 presents the distribution of patients' ages in the CLL study population in which the age range for males and females is very similar. At early (less than 30 years) and late age groups (greater than 80 years) the sex ratios between male and females do not appear to be significant.

Results from the Chi-Square tests and odds ratio analyses are presented in Table 4 . Of the four FISH probes, only the deletion of the 11q22.3 (ATM gene) demonstrated statistical significance in the Chi-Square test (P-value of $0.0049)$. The $\mathrm{OR}$ value of 1.7045 is also significantly different from the $\mathrm{OR}$ values found for the rest of the FISH probes, indicating the male has $70.45 \%$ or $64.35 \%$ higher risk to have abnormal FISH test results for the ATM-FISH probe. This was true for deletions of the ATM gene when found as a sole abnormality $(\mathrm{OR}=1.7045)$ or in combination with other abnormalities which included the deletion of the ATM gene $(\mathrm{OR}=1.6435)$. Both these two categories of single and multiple probe abnormalities strongly indicated that the deletion of the ATM gene was disproportionately over-represented in male CLL patients than in female CLL patients, and that this difference could not be explained by chance alone. These data lead to the conclusion that this mutation was not only found in a higher percentage in males compared to females, but that it was distinct from the $M / F$ sex ratio of $\sim 1.5$ found for the other FISH probes [trisomy 12, $\operatorname{del}(13 q 14.3)$, $\operatorname{del}(17 \mathrm{p} 13.1)]$.

The $0 R$ values for the $M / F$ sex ratios of trisomy 12 , deletion $13 q$, and deletion 17p (TP53 gene) FISH probe abnormalities in either single or multiple combinations were not significantly different from 1.0 and could be explained by chance alone. Therefore, the $\mathrm{M} / \mathrm{F}$ sex ratio for each of the CLL-FISH probe abnormalities appeared to be about the same and not significantly different from an $M / F$ sex ratio of 1.5 .

\section{Discussion}

Although sex ratios in lymphoid neoplasms and other tumors show male predominance, there remains an incomplete understanding of these observations. Our study makes this $\mathrm{M} / \mathrm{F}$ ratio determination based on a study population of patients clinically diagnosed with, or suspected of having CLL for whom FISH studies were conducted. Based on this clinical assignment, a ratio of 1.51 was found, which is congruent with previous studies, ${ }^{5,10}$ indicating similar values or higher. These observations suggest that CLL may have a sex chromosomeinfluenced component determining its transmission. ${ }^{2}$ We also examined the question of what the M/F ratio is in those CLL patients who 
had FISH abnormalities detected by specific genetic probes and found that 3 of the 4 probes had values close to 1.5 and that 1 probe (ATM gene) had a significantly higher $\mathrm{M} / \mathrm{F}$ ratio of 2.54. The coincidence that, like the clinical $\mathrm{M} / \mathrm{F}$ ratio, the genetic $\mathrm{M} / \mathrm{F}$ ratio for 3 probes may simply suggest that in the CLL study population which already has a disproportionately high number of male patients, the likelihood of detecting a genetic abnormality is equally high (in males) and that it may be sex chromosome influenced. However, for the ATM-FISH probe, the M/F ratio was significantly higher $(\sim 2.5)$ than the $\sim 1.5$ ratio found for the other probes and suggests that for this mutation, a special set of conditions necessary for the development of CLL are more effectively enhanced in male than in female patients.

$\mathrm{M} / \mathrm{F}$ values vary depending on the type of cancer and the age of the patient. There are three possible categories of cancers (hematologic and non-hematologic) with respect to altered $\mathrm{M} / \mathrm{F}$ ratios having values ranging from less than 0.50 to over $20.0 .^{11,12}$ Generally, these categories include cancers in which: i) males have a higher risk, ${ }^{13}$ ii) females are more susceptible, ${ }^{10}$ and iii) males and females are equally represented. ${ }^{14}$ It would appear that different mechanisms cause these variable outcomes. However, these reported $\mathrm{M} / \mathrm{F}$ values are phenotypic $M / F$ values which do not take genetic aspects into account. Our survey confirms that in our CLL study population, as indicated in earlier reports the phenotypic $M / F$ sex value is very close to 1.5 . This high phenotypic $M / F$ sex ratio corresponds to cancers in the first category in which common mechanisms of cancer development may exist.

The purpose for using the FISH data from the CLL study population was to initiate a characterization of what the genotypic $M / F$ sex ratio is for each of the FISH probes used. Surprisingly, very much like the phenotypic $M / F$ ratio of $\sim 1.5$ found, our study demonstrated a genotypic $M / F$ sex ratio higher than 1.0 (1.39-2.5) with respect to all CLL FISH probes. It is important to note that the genotypic $M / F$ sex ratio of $\sim 2.5$ found for the deletion of the ATM gene, is markedly skewed in males, and suggests a special mechanism which may involve ATM gene functions which could include DNA fidelity, homologous recombinational repair and chromosomal stability. ${ }^{15}$ Losses and mutations of the ATM gene have been demonstrated in a number of neoplasms including T-lymphocytic leukemia (T-PLL), Bcell chronic lymphocytic leukaemia (B-CLL) and in mantle cell lymphoma (MCL). ${ }^{15-18}$ These reports suggest that loss of a tumor suppressor gene [or loss of heterozygosity ( $\mathrm{LOH})$ ] may be one of many steps leading to a cancerous state in complex diseases with multifactorial contributions. Gender dependent susceptibility to complex diseases could include polygenic mechanisms, epigenetic modulations, and sexchromosome linked genes. ${ }^{19}$

Two possible explanations can account for the skewed $\mathrm{M} / \mathrm{F}$ ratios found in our study (including the ATM FISH probe showing especially high level of deletions in male CLL patients). Explanation \#1 involves the non pseudoautosomal regions (non-PAR) of the $\mathrm{X}$ and Y chromosome, and explanation \#2 which concerns the pseudoautosomal region (PAR) of the sex chromosomes.

Explanation 1: The genotypic M/F sex ratio of $\sim 1.5$ was found for trisomy 12 , deletion of D13S319 at chromosome 13q14.3, and deletion of the TP53 gene. These markers may derive complete function only when complemented by hypothetical X chromosome genes. These hypothetical X-chromosome linked genes appear as a single dose in male cells (hemizygous) and as two (non-PAR, and not X-chromosome inactivated) doses in female cells. If there is a predisposing mutation for any of the three FISH autosomal markers in either males or females, the $C L L-X$ gene product will continue normal function with no CLL development. However, if the CLL-X gene is subsequently mutated in males (hemizygous), gene function of the CLL-gene markers would also be impaired resulting in CLL. However, in females (heterozygous) the second non-mutated $C L L-X$ gene salvages the gene dosage requirement with no development of CLL. Mutations of both $C L L$-X genes in females would be necessary for subsequent CLL development. This explanation is consistent with the observation that CLL typically has an adult age onset, that relatively fewer females succumb to CLL given the salvaging effect of the double doses of the Xlinked CLL genes they possess, and offers a plausible biological/genetic basis for the $\sim 1.5$ sex ratio found for these three important CLL genetic markers. Since ATM loss is considerably higher in males than females, with a genotypic sex ratio of $\sim 2.5$, additional factors are implicated. Other highly skewed phenotypic $M / F$ sex ratios reported in hematological, nonhematological cancers, and in certain solid tumors, can be as high as 28.7 such as for Kaposi sarcoma. ${ }^{9}$ For these entities it may be that mutations are not necessarily disabled by $100 \%$ loss of function. In males after the first ATM mutation, a partially functioning CLL-X gene might contribute to the loss of the $2^{\text {nd }}$ ATM gene. However, in females the two partially functioning CLL-X genes may be result in sufficient DNA repair to prevent ATM loss at a higher level than that found in males. This secondary salvage pathway would provide for a lower rate of ATM gene loss and may represent a relative protective mechanism favoring females. There may also be other models that could explain gender ratio distortions involving multiple DNA-repair related gene families. ${ }^{20}$ Our hypothesis of X-linked DNA repair- related genes is supported by recent mapping of DNA repair genes (which include the APE1, CETN2, TREX2, UBE2A, and RPA4 genes) on the $\mathrm{X}$ chromosome. ${ }^{21}$

Explanation 2: The PAR is homologous in the human $\mathrm{X}$ and $\mathrm{Y}$ chromosomes where they pair during meiosis, and where there are 2 doses for every gene found in this region. Compelling evidence shows that the PAR plays a role in the $\mathrm{M} / \mathrm{F}$ ratio found in mantle cell lymphoma (MCL) which may also apply to CLL. The study demonstrated male predominance in mantle cell lymphoma (MCL) with loss of the Y chromosome and homozygous deletions within the PAR. ${ }^{22}$ In all except 3 of the 21 MCL cases studied, the loss of the $\mathrm{Y}$ chromosome was demonstrated. Furthermore, 2 of the 3 cases (which showed no Y chromosome loss) had biallelic losses of PAR1 in Xp/Yp, and of 16 cases in which there was $\mathrm{Y}$ chromosome loss, an additional case showed biallelic loss of PAR1. The genotypic $1.5 \mathrm{M} / \mathrm{F}$ ratio for the 3 probes used in our study could also be ex plained by mutations/losses of the PAR region of the $\mathrm{X}$ and $\mathrm{Y}$ chromosomes. A similar linkage to the PAR has been proposed for Hodgkin's lymphoma in which the risk for brothers of affected males or sisters of affected females was higher than the risk for siblings of the opposite gender. ${ }^{23}$ Also supporting this explanation is that chemokines and chemokine receptors may play a role in B-cell malignancies, ${ }^{24}$ and that related cytokine-receptor genes map to the PAR of sex chromosomes. ${ }^{25}$ Increasingly, it appears that gender plays a major role in defining not only the identity and nature of some neoplasms but also the mechanisms involved in their origin and progression.

\section{References}

1. Muller-Hermelink HK, Montserrat E, Catovsky D, et al. Chronic lymphocytic leukemia/small lymphocytic lymphoma. In: Swerdlow SH, Campo E, Harris NL, et al eds. WHO classification of tumours of haematopoietic and lymphoid tissues. Geneva, Switzerland: World Health Organization; 2008. pp 180-182.

2. Kirsch-Volders M, Bonassi S, Herceg Z, et al. Commentary: gender-related differences in response to mutagens and carcinogens. Mutagenesis 2010;25:213-21.

3. Nascimento MC, Yamamoto M, Rodrigues MM, et al. CLL: chromosomal abnormalities (FISH) and their relation with clinical stage, CD38 and ZAP-70. Rev Bras Hematol Hemoter 2006;28:5-10.

4. Goldin LR, Pfeiffer RM, LI X, Hemminki K. Familial risk of lymphoproliferative tumors in families of patients with chronic lymphocytic leukemia: results from the 
Swedish Family-Cancer Database. Blood 2004;104:1850-4.

5. Cartwright RA, Gurney KA, Moorman AV. Sex ratios and the risks of haematological malignancies. Br J Haematol 2002;118: 1071-7.

6. Dohner H, Stilgenbauer S, Benner A, et al. Genomic aberrations and survival in chronic lymphocytic leukemia. N Engl J Med 2000;343:1910-6.

7. Hjalmar V, Kimby E, Matutes E, et al. Trisomy 12 and lymphoplasmacytoid lymphocytes in chronic leukemia B-cell disorder. Haematologica 1998;83:602-9.

8. Heim S, Mitelman F, eds. Cancer Cytogenetics $2^{\text {nd }}$ ed. New York: A John Wiley \& Sons, Inc.; 1995. pp 377-379.

9. Cordone I, Masi S, Mauro FR, et al. P53 expression in B-cell chronic lymphocytic leukemia: a marker of disease progression and poor prognosis. Blood 1998;91:4342-9.

10. Cheson BD. Chronic lymphoid leukemias. In: Abeloff MD, Armitage J0, Niederhuber JE, et al eds. Clinical Oncology, $3^{\text {rd }}$ ed. Philadelphia: Elsevier, Churchill, Livingstone; 2004. pp 2921-2939.

11. Cook MB, Dawsey SM, Freedman ND, et al. Sex disparities in cancer incidence by period and age. Cancer Epidemiol Biomarkers Prev 2009;18:1174-82.

12. Horner MJ, Ries LAG, Krapcho M, et al. editors. SEER Cancer Statistics Review.
National Cancer Institute. Available from: http://seer.cancer.gov/csr/1975_2006/.

13. Tabernero MD, Espinosa AB, Maillo A, et al. Patient gender is associated with distinct patterns of chromosomal abnormalities and sex chromosome-linked geneexpression profiles in meningiomas. The Oncologist 2007;12:1225-36.

14. Mauritzson N, Johansson B, Albin M, et al. A single-center population-based consecutive series of 1500 cytogenetically investigated adult hematological malignancies: karyotypic features in relation to morphology, age and gender. Eur J Haematol 1999;62:95-102.

15. Ataxia-telangiectasia mutated gene: ATM. Online Mendelian inheritance in man. Baltimore: Johns Hopkins University Press; 2010.

16. Vorechovsky I, Luo L, Dyer MJS, et al. Clustering of missense mutations in the ataxia-telangiectasia gene in a sporadic Tcell leukaemia. Nature Genet 1997;17:969.

17. Schaffner C, Idler I, Stilgenbauer S, et al. Mantle cell lymphoma is characterized by inactivation of the ATM gene. Proc Nat Acad Sci USA 2000;97:2773-8.

18. Schaffner C, Stilgenbauer S, Rappold GA, et al. Somatic ATM mutations indicate a pathogenic role of ATM in B-cell chronic lymphocytic leukemia. Blood 1999;94:748-
53.

19. Kaminsky Z, Wang SC, Petronis A. Complex disease, gender and epigenetics. Ann Med 2006;38:530-544.

20. Wood RD, Mitchell M, Sgouros J, Lindahl T. Human DNA repair genes. Science 2001;291:1284-9.

21. Lindahl T, Wood RD. Review: quality control by DNA repair. Science 1999;286:1897905.

22. Nielander I, Martin-Subero JI, Wagner F, et al. Recurrent loss of the Y chromosome and homozygous deletions within the pseudoautosomal region 1: association with male predominance in mantle cell lymphoma. Haematologica 2008;94:949-50.

23. Horwitz MS, Mealiffe ME. Further evidence for a pseudoautosomal gene for Hodgkin's lymphoma: reply to The familial risk of Hodgkin's lymphoma ranks among the highest in the Swedish Family-Cancer Database by Altieri A and Hemminki K. Leukemia 2007;21:351.

24. Trentin L, Cabrelle A, Facco M, et al. Homeostatic chemokines drive migration of malignant B cells in patients with nonHodgkin lymphomas. Blood 2004;104:5028.

25. Kremer E, Baker E, D’Andrea RJ, et al. A cytokine receptor gene cluster in the $\mathrm{X}-\mathrm{Y}$ pseudoautosomal region? 1993;82:22-8. 